Original article

\title{
Perspectives of faculty members toward Iranian National Olympiad for medical students: a qualitative study
}

\author{
Saber Azami-Aghdash ${ }^{1}$, Morteza Ghojazadeh ${ }^{2}$, Raha Nazavar ${ }^{3}$, Sina Yaghoubi ${ }^{4}$, Leila Vahedi ${ }^{2}$ \\ ${ }^{1}$ Iran University of Medical Sciences, Tehran, Iran \\ ${ }^{2}$ Tabriz University of Medical Sciences, Tabriz, Iran \\ ${ }^{3}$ Committee Urmia University of Medical Sciences, Urmia, Iran \\ ${ }^{4}$ Tabriz branch Islamic Azad university, Tabriz, Iran
}

Received 1 September 2016, Accepted 13 October 2016

CC 2016, Azami-Aghdash S., Ghojazadeh M., Nazavar R., Yaghoubi S., Vahedi L.

(C) 2016, Russian Open Medical Journal

\begin{abstract}
Objective - Regarding to the status of medical science Olympiads in medical science pedagogy, the views of beneficiaries are needed to be examined on them, in particular, faculty members who are the most interested group in the given issue. As such, the purpose of this study is the evaluation of views of the faculty members on the mission and performance of medical science Olympiads in Iran.

Material and Methods - The data for this qualitative study were collected through semi-structured interviews and then were analyzed using the content-analysis method. Finally, 95 members of faculty board were selected from universities of medical sciences in Iran and data collection continued till data saturation.

Results - Four themes including: points of strength in Olympiads, points of weakness in Olympiads, attitudes of faculty members to Olympiads, and suggestions for better performance of the Olympiads were extracted. The points of strength consisted of: mission, the performing procedures, and the scientific level of the competitions. The points of weakness included: mission, the performing procedures, and the scientific level of the competitions. Most of the participants $(79 \%)$ had positive attitude toward the Olympiads. Participants presented 8 strategies in order to manage the competitions better.

Conclusion - It necessary to do more researches to identify the related problems and to use the required. Applying instructor's points and views on the strengths, weakness, and suggestions can be efficient in policy making, designing and performing medical Olympiads.
\end{abstract}

Keywords: perspectives, strength, weakness, suggestions, scientific Olympiad.

Cite as Azami-Aghdash S, Ghojazadeh M, Nazavar R, Yaghoubi S, Vahedi L. Perspectives of faculty members toward Iranian National Olympiad for medical students: a qualitative study. Russian Open Medical Journal 2016; 5: e0405.

Correspondence to Leila Vahedi. Tel.: +9141042900. Fax:+4133373741. Email: vahedi.149@gmail.com

\section{Introduction}

Scientific Olympiads of medical students take place to foster the problem - solving and reasoning skills, attention to critical and creative thinking, attention to the goals of health system, team work encouragement, and inter disciplinary activities [1].

Scientific Olympiads have a history of 80 years old. Russia was the first country where scientific Olympiads were performed for high school students. The first mathematical Olympiads took place in Leningrad in 1934. Russia used Olympiads to direct talents toward the needs of the country, and the winners of the competitions were accepted in the best universities of the country automatically [2]. The most important advantage of Olympiads was their affordability for the identification of the talented students. After Russia, USA also used similar competitions to identify and employ elites for solving related problems of the country in the 1940s [3].
As medical students are intellectual capitals of a community and have an important role in health improvement, supporting top potentials and creating opportunities for them to grow are the most important duties of educational institutions, and capitalization on talents (valuable potentials) can establish remarkable developments in scientific, social, and economic fields [4].

Significant progresses in medical sciences and on going improvements in prevention and treatment have posed demands for creating changes in educational systems, among them medical universities have the most important role, in particular [5].

It was first in 2009, when the medical students scientific Olympiad was held in Isfahan University [6]. Then, the universities of Shiraz, Tehran, Tabriz, and Kerman were the next hosts of these competitions, respectively. Participants competed in national competitions after succeeding in screening tests which were given to them in their own universities [7]. 
Table1. Demographic information of participants $(n=95)$

\begin{tabular}{|c|c|}
\hline Variables & Value \\
\hline \multicolumn{2}{|l|}{ Gender, no. (\%): } \\
\hline - Male & $64(67.4)$ \\
\hline - Female & $31(32.6)$ \\
\hline \multicolumn{2}{|l|}{ Education, no. (\%): } \\
\hline - Subspecialist & $7(7.4)$ \\
\hline - Specialist & $22(23.2)$ \\
\hline - Professional doctor & $50(52.6)$ \\
\hline - Master student & $16(16.8)$ \\
\hline \multicolumn{2}{|l|}{ Scientific degree, no. (\%): } \\
\hline - Professor & $0(0)$ \\
\hline - Associate Professor & $22(23.2)$ \\
\hline - Assistant Professor & $57(60.0)$ \\
\hline - Tutor & $16(16.8)$ \\
\hline Age, years, $M \pm S D$ & $43.31 \pm 5.41$ \\
\hline History of teaching, years, $M \pm S D$ & $2.78 \pm 6.24$ \\
\hline History of participating in Olympiads, no. (\%) & $57(60.0)$ \\
\hline
\end{tabular}

With respect to the significance and status of Olympiads on the one hand, and the importance and necessity of attention to the quality of its administration on the other hand, it seems vital to determine the strength, the weakness, and the suggestions of instructors regarding better administration of medical students scientific Olympiad tests, and the related problems and shortcomings can be identified and then used for their improvement or elimination. Thus, the present study was conducted in order to analyze the comments of faculty members regarding this issue.

\section{Materials and Methods}

This is a qualitative study. It has been done to evaluate the views and attitudes of Iranian faculty members of medical sciences universities. Participants of this study were faculty members of universities of medical science of Iran. They were selected because they had a lot of experience in teaching and managing these Olympiads, and they had needed information and rich knowledge about the different stages of competitions.

In order to be included in the experiment, the criterion was: introduction of the instructors from the related medical universities. The sampling method which was used to select the participants was based on the purpose of the study, i.e. it was heterogeneous because of different universities, courses teaching history, different science - degrees, and different fields which were used in this study. In this method, those who had the most and richest information, and were familiar with the goals of Olympiad competitions, and were involved in their scientific and administrative problems, and were also able to convey their information to the researches properly, were selected as samples. This process continued till data saturation. By the time the researcher felt that extra information couldn't be obtained by continuing the sampling process [8]. This stage of the study ended with 95 participants as samples of the study.

In order to collect data, open ended questionnaires and semistructured interviews were used. Questionnaires consisted of two parts:

Demographic information and 4 open questions as follow: points of strength in competitions, points of weakness in competitions, attitudes of the instructors, and finally required suggestions on the problems.

Questionnaires were distributed to instructors during their break time when they had some free time to answer the written questions and while distributing the questionnaires; their comments were collected through a short interview. Duration of each interview differed from 20 to 30 minutes. Their comments were recorded by the use of a sound recording device by their own willingness and consent. Moreover, interviewers even used note writing during the interviews. The content of the interviews were reheard by the researchers several times immediately after the end of each interviews, and were transcribed in word 2010 software. In order to analyze the obtained data, content analysis was used, and for data consistency or rigor, peer check and immersed methods were used [4]. At the beginning of te study, the objectives of the experiment were explained to the participants in order to meet ethical issues. Thus, they agreed to take part in the study. Meanwhile, the individuals had the right of leaving the study at any moment they decided.

\section{Results}

Demographic information of participants is shown in Table 1.

In this study, after analyzing and coding the comments of participants on the issue, 4 themes including: the points of strength in Olympiads, the points of weakness in Olympiads, the views of faculty members about the Olympiads, and their suggestions for better performance in Olympiads were extracted.

The points of strength were grouped in 3 themes and 10 subthemes. Theme and some samples from the utterances of participants were summarized in Table 2.

Another major theme which was extracted from the perspectives of participants was the weakness of competitions which was grouped in 3 main domains and subdomain categories (Table 3).

From the perspective of the faculty board members medical science universities in Iran ( $n=95)$ by examining and analyzing the views and attitudes at participants, two main themes including, "positive attitude" and "negative attitude" were specified, which are mentioned briefly.

\section{Positive attitude}

In this study, 83 participants (87\%) had positive attitudes toward previously held Olympiads.

In line with this, participant No.18 says: "Students who take part in Olympiads, in comparison with other students, have different views and attitudes, and their creativity and sense of analysis have increased, even their confidence has improved".

Or on this case, participant No.54, says: "All in all, it is an interesting idea, and the students' knowledge and skills are compared with other students. Field combination has been paid attention and the innovative aspect of Olympiads acts as a key factor in controlling medical activities, and ...". Also, participant No.72 states his opinion on this case as "Fortunately, Olympiad is held every year in different universities not just centralized in Tehran, the experiences of host universities increase and students become familiar with the cultures of other cities and universities in our country which is very valuable regarding its cultural aspect". 
Table 2. Points of strength of medical science Olympiads in Iran from the perspective of the faculty members in medical sciences universities of Iran ( $\mathrm{n}=95$ )

\begin{tabular}{|c|c|c|}
\hline Participants statements & Sub-Them & Them \\
\hline \multirow{3}{*}{ Mission } & Student & $\begin{array}{l}\text { - Olympiad was a new idea for recognizing talented students (participant No.1). } \\
\text { - Increasing student's creativity (participant No.5). } \\
\text { - Being familiar with students from other universities and paying attention to some aspect of knowledge } \\
\text { in medicine which was hidden (participant No.8). }\end{array}$ \\
\hline & $\begin{array}{l}\text { Faculty member } \\
\text { (instructor) }\end{array}$ & $\begin{array}{l}\text { Familiarity of the instructor with the modern educational methods and transfer of them to the } \\
\text { students (participant No.10). } \\
\text { - The interaction between faculty board members from different universities (participant No.43). } \\
\text { - Considering the scholarship score of faculty members (participant No.89). }\end{array}$ \\
\hline & University & $\begin{array}{l}\text { - Creating scientific incentives and collaboration among faculty members and students (participant } \\
\text { No.69). } \\
\text { - Better relationships and exchange of finding among universities (participant No.79). }\end{array}$ \\
\hline \multirow{3}{*}{ Scientific points } & References & $\begin{array}{l}\text { - References were announced on time (participant No.56) } \\
\text { - References were provided as CDs and books by the host universities and were put in access of other } \\
\text { universities (participant No.21). }\end{array}$ \\
\hline & Questions & $\begin{array}{l}\text { - The design of questions was used as accept map (participant No.45). } \\
\text { - The security of questions was too excellent (participant No.89). }\end{array}$ \\
\hline & Tests & $\begin{array}{l}\text { - Some of tests were in the form of open - book. } \\
\text { - OSCE tests and case-study were used ( participant No.75). } \\
\text { - Tests were divided into individual and group tests (participant No.26). }\end{array}$ \\
\hline \multirow{5}{*}{ Operational points } & Informing & $\begin{array}{l}\text { The site of Olympiad is active and up to date ( participant No.28). } \\
\text { - There was a proper conformity with informing schedule from the given site (participant No.37). }\end{array}$ \\
\hline & $\begin{array}{l}\text { Program } \\
\text { management }\end{array}$ & $\begin{array}{l}\text { Planning / scheduling was appropriate with respect to time limit and time interfere with academic } \\
\text { programs (participant .No.50). } \\
\text {-The different stages of Olympiad were performs appropriately (participant No .65). }\end{array}$ \\
\hline & & - The halls for completions were selected appropriately and they were perfect (participant No.68). \\
\hline & $\begin{array}{l}\text { Welfare and } \\
\text { relational facilities }\end{array}$ & $\begin{array}{l}\text { - The tourism programs during Olympiad administration were good (participant No.17). } \\
\text { - Hospitality was moderate (participant No.30). } \\
\text { - Suitable service was provided for students (participant No.36). }\end{array}$ \\
\hline & Personal/ staff & $\begin{array}{l}\text { - Appropriate staff is selected for Olympiad administration (participant No.50). } \\
\text { - Host team act perfectly (participant No.91). }\end{array}$ \\
\hline
\end{tabular}

Table 3. Points of weakness of medical science Olympiads in Iran from the perspective of the faculty members in medical science universities of Iran ( $\mathrm{n}=95$ )

\begin{tabular}{|c|c|c|}
\hline Participants statements & Sub-Them & Them \\
\hline \multirow{3}{*}{ Mission } & Student & $\begin{array}{l}\text { - The questions are posed at medical student level while other fields don't welcome them ( participant No.83). } \\
\text { - Students awards are at a lower level, and so are the immaterial facilities. } \\
\text { - As time passes, the tests have been similar to pre-university entrance examination, and this causes } \\
\text { extreme stress in students (participant No.78). }\end{array}$ \\
\hline & Faculty member & For faculty members of universities low levels of privileges are considered (participant No.21) \\
\hline & University & $\begin{array}{l}\text { - Typ } 2 \text { and type } 3 \text { universities are not included in designing and modifying of the questions (participant No.3). } \\
\text {-Any innovative and creative projects are not observed offer examinations which make Olympiads } \\
\text { similar to other ordinary exams (participant No.46). } \\
\text { - The purpose of some universities is just to obtain score but knowledge (participant No.10). }\end{array}$ \\
\hline \multirow{3}{*}{ Scientific points } & References & - References are announced just according to the comments of some instructors. (Participant No.88). \\
\hline & Questions & $\begin{array}{l}\text { - Type of questions the designers, exam procedure and the method of evaluation are sometimes vague } \\
\text { (participants No.44). } \\
\text { - Some questions are repetitive and must be memorized (participant No.60). } \\
\text { - It is better for questions not to examine just the erotically but the real problems of the real problems of } \\
\text { the country practically (participant No.66). }\end{array}$ \\
\hline & Tests & $\begin{array}{l}\text { - The answering time was not in infirmity with the number and type of questions (participant No.76). } \\
\text { - The correct answers are not revealed immediately after the examination, and they are not analyzed as } \\
\text { well (participant No.68). } \\
\text { - There was a delay in the announcement of the results in spite of the different dates which were } \\
\text { identified and the exact time (participant No.20). }\end{array}$ \\
\hline \multirow{3}{*}{ Operational points } & Informing & $\begin{array}{l}\text { - Whatever is going to happen about the Olympiad, should appear in the site openly (participant No.5) } \\
\text { - Questions and correct answers are not uploaded on the site after examinations (participant No.68). }\end{array}$ \\
\hline & $\begin{array}{l}\text { Program } \\
\text { management }\end{array}$ & $\begin{array}{l}\text { The topics which are to be discussed in Olympiads are announced late, so it doesn't have any significant } \\
\text { effect on the university campus (Participant No.54). } \\
\text { - Inconsistency is seen booth in the time of test-administration and time of results announcement } \\
\text { (participant No.85). }\end{array}$ \\
\hline & $\begin{array}{l}\text { Welfare and } \\
\text { relational facilities }\end{array}$ & $\begin{array}{l}\text { - There was not proper snack in hotels (participant No.30). } \\
\text { - The number of participants was so great then we preferred not to take part in the exam (participant } \\
\text { No.12). }\end{array}$ \\
\hline
\end{tabular}


Table 4. Suggestions of participants for designing and performing effective and proper Olympiads in Iran and the removal of the eventual barriers ( $\mathrm{n}=95$ ) Participants statements

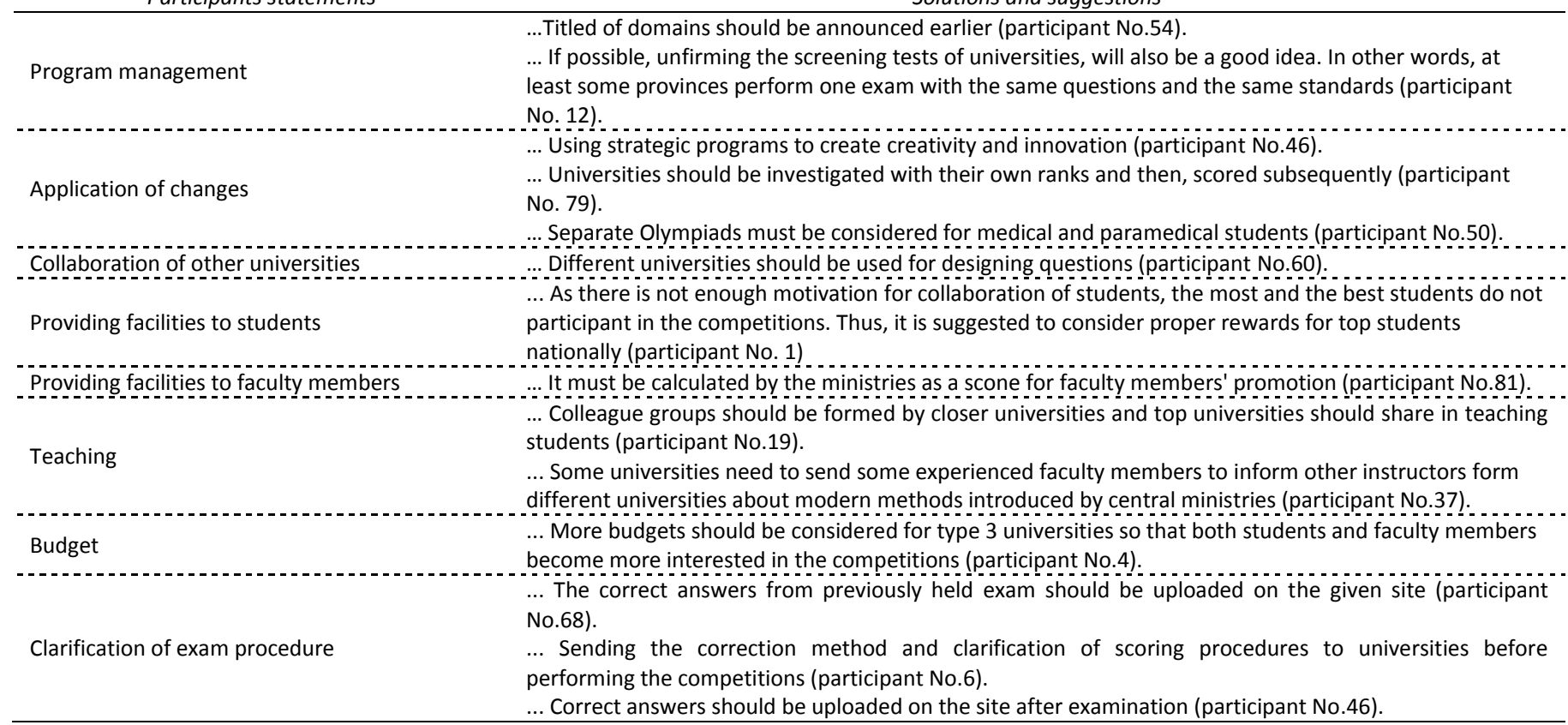

\section{Negative attitude}

While the views and attitude of most participants were positive, a number of participants didn't have positive views and attitudes toward this case. For example, participant number 40 asserted, "in my opinion, the Olympiads that we administer, merely serves as a duty fulfillment, because it takes about 3 to 4 months from holding meetings on how well to perform Olympiads" to final exam and announcement of results subsequently.

Therefore, Olympiads don't have a salient benefit.

Some of the participants believe that their negative attitudes toward Olympiads are due to the ignorance of main purposes which are not fulfilled properly. Participant No.92 stated his opinion on this issue as: "the goal is just to win, and there is no healthy competition among the participants, changes are low, and no projects are seen after and of the programs, motivation ...."

Another participant said that lack of justice is the factor of his negative attitude with respect to this; participant No.3 believed that "Olympiad program is not beneficial or helpful for most students; on the other hand, those students who participated in the competition was not satisfied with its administration".

In this study, participants were asked to offer their solutions and suggestions about effective and proper administrations of Olympiads, and the removal of the eventual barriers.

By analyzing and encoding the suggestions and solutions offered by participants, finally, 8 solutions and suggestions were specified, which are shown in Table 4, accompanied by the participants' utterances/direct speeches.

\section{Discussion}

The scientific Olympiads of medical students across the country is an idea which is in line with the identification of top students, and during the past years, 5 periods of it were held in the different universities of Iran with respect to the sensitivity and importance of administration in the competitions, the need to exam in the philosophy, necessity, achievement, costs, hinders, and promotional strategies is felt. In this study, the views and attitudes of experts, regarding mentioned issues, were considered both qualitatively and quantitatively.

The results showed that the points of strength and weakness, regarding "design" and "performance" of the competitions are related to aspects of scientific mission and administration in Olympiads. Most participants had positive attitude toward this program. From the participants' point of view, 8 solutions were offered for designing and better administration of this program.

As it can be observed in previously done researches, on the issue of administrating scientific Olympiads in the health systems, promotion as well as maintenance of health in country $[3,6]$, improving skills of problem-solving and reasoning [9], attention to critical and creative thinking, attention to goals of health discipline, encouraging team-work and interdisciplinary activities, increasing students' confidence, increasing practical and scientific capacity of the students, helping students to select their future jobs [10], improving students' scientific abilities are among necessities and philosophy of holding such Olympiads [11].

In this study, also, the factors which were mentioned above were referred to as point of strength in Olympiads by the participants.

According to the results obtained from study, based on the reports announced by scientific Olympiad site of Iran science department, the purpose of performing Olympiad competitions, is to discover talented students and encourage them to research during their education, and create proper opportunities for improving their scientific capabilities [12].

Therefore, by observing the philosophy and necessity of performing scientific Olympiads, we can take the required 
measures in line with efficiency and productivity of Olympiads which are in line with these necessities and philosophies, as well.

In addition, Olympiad competitions lead to design of programs for increase self-efficacy and decrease stress amongst medical students. Vahedi et al have conducted a study on students who had participated in the 4th National Olympiad of Medical Sciences Universities in Iran. They have concluded that mental and physical health associated with self-efficacy and stress therefore, these competitions help to design programs to reduce stress among and increase self-efficacy amongst medical students until the afterwards be able to go into the academic activities [13].

The appropriate quality of question like using conceptual mapping in the fields of basic fundamental science, and key feature tests, clinical reasoning problems, and the scenario for designing question in other fields were considered the points of strength from the perspective of participants in the medical science Olympiads. Although some of the instructors were not satisfied with the limitation of question design, they seemed somehow acceptable. In this regard, Ghojazadeh and et al by evaluating the fundamental questions which were mostly based on conceptual mapping, they relatively assessed appropriate questions, and emphasized on the application and capability of conceptual mapping in measuring students' abilities and skills and, in consequence, the practicality of this method in designing questions [14]. As such, with respect to capabilities and implications of conceptual mapping in teaching and evaluating medical science [5] using this method can have positive effects on promoting the questions of Olympiad questions.

Also, with regard to limiting the designing of questions to a few instructors, the problem can be removed by forming a national bank of questions. Accordingly, in this system, all instructors from all universities with different fields of study can send their designed questions through a designed system, to several department of Olympiad administration. With regard to negative points, one of the most important points of weakness, which was referred to by some participants, was the low collaboration of type $2 \& 3$ universities in planning, designing, and correcting questions, and even their competing with universities of type 1 . In this regard, Adib and et al. by referring to reports from the first period of Olympiad conception in Isfahan stated that successful and efficient administration of Olympiads requires high and proper collaboration of all universities [15].

With respect to the importance and collaboration of all universities in performing more efficient medical Olympiads, the reasons for their lack of interest to collaborate should be identified. In this regard, we must pay attention to two issues, whether the reason lower collaboration of type $2 \& 3$ universities was because of their own lack of interest, or it was because of the authorities or administrators' (of Olympiads) lack of interest to let them collaborate. If the answer is positive to the first part of the above question, then attempts must be made to heighten the collaboration of these universities by creating proper incentives and providing appropriate grounds for them to show their talents. However, if the second part of the above question is a positive, then, the problem can be solved by revising and correcting administrative procedures and providing proper conditions. Regarding the participation of all three types of universities in one competition, it is possible to use the experiences of the universities ranked as type one in performing workshops in other universities [16]. Another point of weakness, from the perspective of participations is inadequate and weak incentives, both for faculty members and for medical students who are involved in these competitions. Undoubtedly donating some golden coins or medals, and a few privileges cannot be a good motive for participating in such a high level of national scientific competitions [17]. In India, the ministry of technology and science, not only donates proper financial awards, but also it allocates scholarship to students who have got universal achievement in competitions, which facilitates their access to the high levels of occupations [16]. Like the international Olympiads in which medals and rewards are distributed among all participation [17], it is suggested to devote the rewards to a large number of participations in order to motivate them and avoid their disappointment and failure in the competitions. Accordingly, with respect to the role of motivation and encouragement in forming a knowledge-based society with software movements, the issue of incentives must be considered as a key factor for those who involve in organizing and administrating scientific Olympiads [18].

Another point of weakness which was forgotten in the administration of Olympiads was its mission, as the only goal of some universities is just getting score and ranks on the other hand, no innovation or creative projects can be observed after the competitions. Therefore, both students and instructors must know that scientific competitions of Olympiad are similar to other scientific, and the goal is to present a significantly scientific test by the participation, in other words, the goal is to promote collaboration among societies, to create job opportunities, to improve industry and to establish relationships between governments and universities.

One of the weak points of this study was its time limit in which data were collected. Because with respect to the restricted period of competitions and the fatigue of faculty members, the possibility of longer interviews was not provided, and for this reason, the time of most interviews was short or open-question questions were used, instead.

\section{Conclusion}

From the perspective of faculty members, improving the skills of problem-solving and reasoning, paying attention to creative and critical thinking, encouraging team-work and interdisciplinary activities, developing relations among universities and students are among the important points of strength in Olympiads. Also, restricting the designing of questions just to a limited number of faculty members, providing inadequate incentives to participations and lack of extracting new ideas from the explanatory exam are among the most important points of weakness in medical students' Olympiads. The solutions, which were presented in this study, can be used for better achievements in Olympiads held in near future.

\section{Acknowledgment}

The authors would like to thank all participants of the study and the staff of the Education Development Center (EDC), Tabriz-Iran for their collaboration.

\section{Conflict of interest}

There is no conflict of interest. 


\section{References}

1. Vahedi L, Hazrati H, Ghojazadeh M, Azami Aghdash S, Rassoli N. Role of talented student office in encouraging medical science students for participating in scientific olympiads. Res Dev Med Educ 2015, 4(2), 177181. DOI: $10.15171 /$ rdme.2015.031.

2. Rous J. The year 1980--the year of the Czechoslovak Spartakiad and Moscow Olympiad (author's transl). Cas Lek Cesk 1981; 120(16): 465469. Czech. PMID: 7285078.

3. Adibi P, Hadagar A, Hadizadeh F, Haghjoo Sh, Monajemi A. Medical science olympiad: concepts, discieplines and methods. Isfahan: Isfahan University of Medical Sciences Publication, 1998. Persian

4. Farajollahi A, Amini A, Rashidi M, Shahbazi A, Azami Aghdash S. The situation analysis of the international relations management and interuniversity collaboration in Tabriz University of Medical Sciences, Iran, during the years 2005-2010. J Analyt Res Clin Med 2013; 1(1): 9-15. DOI: $10.5681 /$ jarcm.2013.004.

5. Ghojazadeh $M$, Aghaei $M H$, Naghavi-Behzad $M$, Piri R, Hazrati $H_{\text {, }}$ Azami-Aghdash S. Using concept maps for nursing education in Iran: a systematic review. Res Dev Med Educ 2014; 3(1): 67-72. DOI: 10.5681/rdme.2014.014

6. Amini M, Kojuri J, Karimian Z, Lotfi F, Moghadami M, Dehghani MR, et al. Talents for future: report of the second national medical science Olympiad in Islamic republic of Iran. Iran Red Crescent Med J 2011; 13(6): 377-381.

7. Khoshbaten M. Fourth supplements of science the Olympiad of medical universities students throughout the country. Jahan Ghazi Publication, 2013. Persian

8. Ghojazadeh M, Hajebrahimi S, Azami-Aghdash S, Pournaghi Azar F, keshavarz M, Naghavi-Behzad M, et al. Medical students' attitudes on and experiences withon evidence-based medicine: a qqualitative study. Journal of Evaluation in Clinical Practice 2014; 779-785. DOI: 10.1111/jep.12191.

9. Hazrati H, Gavgani VZ, Ghojazadeh M, Vahedi L. Problem-based learning in dentistry and interfiled comparison: a citation analysis study. Russian Open Medical Journal 2016; 5: e0302. DOI: 10.15275/rusomj.2016.0302.

10. Tirri K. Actualizing mathematical giftedness in adulthood. URL: http://www.eric.ed.gov/PDFS/ED449587.pdf [accessed 2011 Apr 05]

11. Heller KA, Viek P. Support for university students: individual and social factors. In: Developing talent across the lifespan. London: Psychology Press, 2000.

12. NOET. International scientific mathematics and chemistry Olympiads for university students. URL: http://olympiad.sanjesh.org/en/index.asp [accessed 2011 Apr 05].

13. Vahedi L, Ghojazadeh M, TaleschianTabrizi N, Kolahdouzan K, Chavoshi $M$, Rad B, et al. Impact and amount of academic self-efficacy and stress on the mental and physical well-being of students competing in the 4th Olympiad of Iranian universities of medical sciences. Res Dev Med Educ 2014; 3(2): 99-104. DOI: 10.5681/rdme.2014.020.

14. Hojazadeh M, Ahmadi S, Hosseini MA, Shahabi Sh, Tahamtani T, Nourbakhsh F, et al. Assessment of scientific thinking in basic science questions in the Iranian Fourth National Olympiad for medical sciences students. J Anal Res Clin Med 2014; 2(3): 142-151. DOI: 10.5681/jarcm.2014.024.

15. Adibi $P$, Hadadgar A, Hadizadeh F, Monajemi AR, Eftekhari H, Haghjoo Javanmard $\mathrm{S}$, et al. Implementation of the first medical science olympiad in Iran: a report. Iranian Journal of Medical Education 2000; 10(5): 1006-1017.

16. Mahajan B. Biology Olympiad program in India. Current Science 2000; 79(8): 1085-1061

17. O'Kennedy R, Burke $M$, Van Kampen $\mathrm{P}$, James $\mathrm{P}$, Cotter $\mathrm{M}$, Browne W. The first EU Science Olympiad (EUSO): a model for science education. Journal of Biological Education 2005; 39(2): 58-61.
18. Campbell JR, Wagner $\mathrm{H}$, Walberg HJ. International handbook of research on the development of giftedness and talent. 1st ed. Oxford: Pergamon Press Inc, 2000.

\section{Authors:}

Saber Azami-Aghdash - PhD students in Health Policy, Health Management and Economics Research Center, Iran University of Medical Sciences, Tehran, Iran.

Morteza Ghojazadeh - Associate Professor of Physiology, Liver \& Gastrointestinal Disease Research Center, Tabriz University of Medical Sciences, Tabriz, Iran.

Raha Nazavar - Student, Committee Urmia University of Medical Sciences, Urmia, Iran.

Sina Yaghoubi - Graduated of Veterinary Medicine, Tabriz branch Islamic Azad university, Tabriz, Iran.

Leila Vahedi - MD, PhD by Research, Liver \& Gastrointestinal Disease Research Center, Tabriz University of Medical Sciences, Tabriz, Iran. 